Article

\title{
Development of Novel Hybrid Models for Prediction of Drought- and Stress-Tolerance Indices in Teosinte Introgressed Maize Lines Using Artificial Intelligence Techniques
}

\author{
Amarjeet Kumar ${ }^{1}$, Vijay Kumar Singh ${ }^{2, * \mathbb{D}}$, Bhagwat Saran ${ }^{3}$, Nadhir Al-Ansari ${ }^{4} \mathbb{D}_{\text {, Vinay Pratap Singh }}{ }^{5}$, \\ Sneha Adhikari ${ }^{6}$, Anjali Joshi ${ }^{7}$, Narendra Kumar Singh 8 (D) and Dinesh Kumar Vishwakarma $9, * \mathbb{D}$
}

check for updates

Citation: Kumar, A.; Singh, V.K.; Saran, B.; Al-Ansari, N.; Singh, V.P.; Adhikari, S.; Joshi, A.; Singh, N.K.; Vishwakarma, D.K. Development of Novel Hybrid Models for Prediction of Drought- and Stress-Tolerance Indices in Teosinte Introgressed Maize Lines Using Artificial Intelligence Techniques. Sustainability 2022, 14, 2287. https://doi.org/ $10.3390 /$ su14042287

Academic Editor: José Manuel Mirás-Avalos

Received: 31 January 2022

Accepted: 14 February 2022

Published: 17 February 2022

Publisher's Note: MDPI stays neutral with regard to jurisdictional claims in published maps and institutional affiliations.

Copyright: () 2022 by the authors Licensee MDPI, Basel, Switzerland. This article is an open access article distributed under the terms and conditions of the Creative Commons Attribution (CC BY) license (https:// creativecommons.org/licenses/by/ $4.0 /)$.
1 Department of Genetics and Plant Breeding, MTTC \& VTC, Selesih, Central Agricultural University, Imphal 795004, Manipur, India; amarjeetgpb@gmail.com

2 Faculty of Agriculture Science and Technology, Mahatma Gandhi Kashi Vidhyapith, Varanasi 221002, Uttar Pradesh, India

3 Department of Soil and Water Conservation Engineering, College of Technology, G.B. Pant University of Agriculture and Technology, Pantnagar 263145, Uttarakhand, India; saran.bhagwat007@gmail.com

4 Department of Civil, Environmental and Natural Resources Engineering, Lulea University of Technology, 97187 Lulea, Sweden; ir.alansari@ltu.se

5 Department of Plant Physiology, College of Agriculture-Ganj Basoda, Vidisha 464221, Madhya Pradesh, India; drvpsingh10@gmail.com

6 ICAR—Regional Station, Indian Institute of Wheat and Barley Research, Regional Station Flowerdale, Shimla 171002, Himachal Pradesh, India; snehaadhikari24@gmail.com

7 Genetics and Tree Improvement Division, Arid Forest Research Institute, Jodhpur 342005, Rajasthan, India; anjali99aj@gmail.com

8 Department of Genetics and Plant Breeding, G.B. Pant University of Agriculture and Technology, Pantnagar 263145, Uttarakhand, India; narendraksingh2@gmail.com

9 Department of Irrigation and Drainage Engineering, College of Technology, G.B. Pant University of Agriculture and Technology, Pantnagar 263145, Uttarakhand, India

* Correspondence: vijaysinghswce@gmail.com (V.K.S.); dinesh.vishwakarma4820@gmail.com (D.K.V.); Tel.: +91-9670791406 (D.K.V.)

Abstract: Maize (Zea mays subsp. mays) is a staple food crop in the world. Drought is one of the most common abiotic challenges that maize faces when it comes to growth, development, and production. Further knowledge of drought tolerance could aid with maize production. However, there has been less study focused on investigating in depth the drought tolerance of inbred maize lines using artificial intelligence techniques. In this study, multi-layer perceptron (MLP), support vector machine (SVM), genetic algorithm-based multi-layer perceptron (MLP-GA), and genetic algorithm-based support vector machine (SVM-GA) hybrid artificial intelligence algorithms were used for the prediction of drought tolerance and stress tolerance indices in teosinte maize lines. Correspondingly, the gamma test technique was applied to determine efficient input and output vectors. The potential of the developed models was evaluated based on statistical indices and graphical representations. The results of the gamma test based on the least value of gamma and standard error indices show that days of anthesis (DOA), days of silking (DOS), yield index (YI), and gross yield per plant (GYP) information vector arrangements were determined to be an efficient information vector combination for the drought-tolerance index (DTI) as well as the stress-tolerance index (STI). The MLP, SVM, MLP-GA, and SVM-GA algorithms' results were compared based on statistical indices and visual interpretations that have satisfactorily predict the drought-tolerance index and stress-tolerance index in maize crops. The genetic algorithm-based hybrid models (MLP-GA and SVM-GA) were found to better predict the drought-tolerance index and stress-tolerance index in maize crops. Similarly, the SVM-GA model was found to have the highest potential to forecast the DTI and STI in maize crops, compared to the MLP, SVM, and MLP-GA models.

Keywords: drought-tolerance index; stress-tolerance index; MLP; SVM; MLP-GA; SVM-GA; genetic algorithm 


\section{Introduction}

Agriculture is vulnerable to climate change at the global level. Climate change is a major concern, and has adverse impacts on food production, food quality, and food security [1]. Maize (Zea mays subsp. mays) belongs to the Poaceae family, an important staple cereal crop for food, livestock feed, and biofuels globally. After the green revolution, again, there is a challenge and responsibility in front of plant breeders to increase the production of maize to provide sufficient food for the fast-growing world population. According to data published by the USDA, the global maize production was 1070.51 metric tons during 2016-2017. The total acreage of maize production was 183.76 million hectares, with a productivity of 5.83 tons/hectare. Maize is India's third most important cereal crop, after rice and wheat. India is one of the major maize-producing countries globally with a production of 26 million tons and a productivity of 2.71 tons per hectare in the year 2016-2017, from an area of about 9.6 million hectares.

Maize is growing across the globe. The maize crop is sensitive to several biotic and abiotic stresses. The major abiotic stresses, i.e., drought, heat, waterlogging, and soil salinity or acidity, reduce the production and productivity of crop plants. The most deleterious among abiotic stresses, which restrict optimum crop production and productivity, is considered a drought stress [2]; a total of 20-25 percent of the maize cultivation area is affected by drought throughout the world [3]. The world's agriculture is facing different abiotic problems in different areas simultaneously. The large area is affected by moisture stress during the life span of crops due to erratic climate behaviour. As a result, developing climate-proof genotypes as well as a drought-prediction model to battle these abiotic pressures is critical in order to feed the growing population. The focus should be given to simplifying the concept of the genetics of the complex mechanisms of drought.

Therefore, there is a need to understand the mechanism and behaviour of drought. Drought, in terms of agriculture, may be defined as "a specific condition whereby there is the unavailability of adequate moisture content in the soil at different stages of plant growth to meet their needs" [4]. The meaning of drought tolerance, in the case of any plant species, is generally understood in terms of ensuring that their survival and productivity are always determinant [5]. The mechanism of drought tolerance is quite complex and complicated due to the involvement of several factors. Therefore, selection for drought tolerance is always a tedious job due to interactions between genotypes and environmental factors, which restricts knowledge about the mechanism of drought, the contributions of different factors, and the interactions among factors of tolerance [6]. Under drought stress, there is a significant change in the physiology of cells, and finally, the response of a crop species ultimately affects the leaf water content, transpiration rate, leaf rolling, photosynthesis, and water use efficiency (WUE). Due to a lack of sufficient information about the mechanisms of drought tolerance, drought tolerance can be quantified based on grain yield under dry conditions [7]. The nature of the drought is unpredictable and erratic. The recurrent nature becomes a permanent feature under the global climate change scenario. Therefore, it is an urgent need to predict the occurrence of drought stress.

Artificial intelligence is widely employed in various fields, including computer science, robotics, engineering, medical, translation, economics, business, and psychology. Several investigations in the literature reveal that artificial intelligence produces findings in modeling approaches that seem to be close to the actual information when solving linear, complex, and other systems. We review the present state of the art and the advancements in artificial intelligence modeling for various natural processes, such as wilting point [8], soil temperature [9,10], soil moisture [11], evaporation [12-15], soil permeability [16,17], evapotranspiration [18], silt [19], solar radiation [20], water quality [21], stage-discharge [22], and runoff [23], that affect crops at different stages. Artificial intelligence technologies are also popular in social engineering attacks [24], such as the Off-line Handwritten Signature Verification System [25]. It was found that no effective model was developed in the past to predict drought- and stress-tolerance indices for any crops, other than the regression-based 
model. The prediction potential of the regression-based model was very low compared to artificial intelligence (AI) predictability [26,27].

Therefore, multilayer perceptron (MLP) and support vector machine have been the most popular and wildly used artificial intelligence techniques to solve various problems in the last few decades. Darbandi and Pourhosseini [28] used the gamma test to determine the optimal inputs arrangement of the systems. Subsequently, MLP and hybrid multilayer perceptron were also used to estimate periodic stream flows for such a series of time increments while employing actual data. The results suggested that the hybrid multilayer perceptron model was acceptable for periodic stream-flow modeling in the research area.

In contrast, the MLP model performs poorly compared to the hybrid multilayer perceptron model. Heddam et al. [29] studied the utility and capability of four different AI models. The results of the AI models showed strong and useful techniques for forecasting pigment concentrations using simple water quality indicators as variables. Oliveira et al. [30] studied the applicability of MLP and remote sensing to estimate coffee tree volume using vegetative indices from various areas of plants. The results suggested that the performance of MLP and remote sensing were satisfactory for the estimation of coffee tree volume. Mehmet et al. [31] used the SVM and MLP models for the prediction of drought and also compared the potential of empirical decomposition and the different wavelet networks. Sareh et al. [32] studied the five different AI and hybrid AI algorithms to predict water infiltration. The results indicated that the performances of the hybrid AI models were more reliable compared to the conventional AI models. After reviewing the potential applications of artificial intelligence in various fields, we decide that multilayer perceptron, support vector machine, and their hybrids with genetic algorithm models can be used to develop a novel prediction model. It is necessary to develop a novel approach for forecasting droughtand stress-tolerance indices for crops. Hence, our hypothesis was to develop a novel hybrid model for the prediction of the drought-tolerance indices and stress-tolerance indices based on multilayer perceptron (MLP), support vector machine (SVM), genetic algorithm-based hybrid multilayer perceptron (MLP-GA), and genetic algorithm-based hybrid support vector machine (SVM-GA) models. In addition, superior input-output combinations were developed via gamma test.

\section{Materials and Methods}

\subsection{Data Collection}

The current investigation was performed at N. E. Borlaug Crop Research Centre, G. B. Pant University of Agriculture and Technology, Pantnagar, Uttarakhand, India. The planting materials were wild progenitor teosinte (Z. mays ssp. parviglumis) and a maize inbred line DI-103. Teosinte, as a pollen parent, and maize inbred line DI-103 were crossed in kharif, 2015, and one was backcrossed with DI-103 as a recurrent parent to develop $\mathrm{BC}_{1} \mathrm{~F}_{1}$ lines. Subsequently, in kharif, 2016, selfing was performed to produce $203 \mathrm{BC}_{1} \mathrm{~F}_{2}$ lines, which were evaluated in the rabi, 2016-2017 for drought tolerance. The present investigation comprised an evaluation of 203 lines, the individuals of each line was progeny of a single plant. The lines were sown in rabi, 2017, for evaluation. These lines were grown as a single row in two environmental situations, i.e., irrigated and moisture-stress conditions, during rabi, 2016-2017 for the phenotyping of the morpho-physiological traits associated with drought tolerance. The moisture stress was created to evaluate 203 lines at the reproductive stage, i.e., during the flowering period. Each row was 2-m long, and the plant-to-plant distance was $75 \mathrm{~cm}$. The observations were taken in both environments for different morphological traits, i.e., days to anthesis (DOA), days to silking (DTS), days to the senescence (DTS), plant height (PHt), ear length (EL), number of kernels (NK), gross yield per plant (GYP), and the drought-tolerance index (DTI) as well as the stress-tolerant 
index (STI) were calculated to quantify the drought tolerance. The drought-tolerance index and stress-tolerance index were calculated with the following formula:

$$
\mathrm{DTI}=\frac{\mathrm{Y}_{\mathrm{s}} \times\left(\frac{\mathrm{Y}_{\mathrm{s}}}{\mathrm{Y}_{\mathrm{p}}}\right)}{\overline{\mathrm{Y}}_{\mathrm{s}}}
$$

where DTI = drought tolerance index, $\mathrm{Y}_{\mathrm{s}}=$ yield in stress conditions for each genotype, $\mathrm{Y}_{\mathrm{p}}=$ yield in non-stress conditions for each genotype; $\overline{\mathrm{Y}}_{\mathrm{s}}=$ yield mean in stress conditions for all genotypes and $\bar{Y}_{p}=$ yield mean in non-stress conditions for all genotypes [21].

$$
\mathrm{STI}=\frac{\mathrm{Y}_{\mathrm{s}} \times \mathrm{Y}_{\mathrm{p}}}{\overline{\mathrm{Y}}_{\mathrm{p}}}
$$

$Y_{s}=$ stress yield of a given genotype and $Y_{p}=$ optimal (potential) yield of a given genotype, $\bar{Y}_{\mathrm{s}}=$ average yield of all genotypes under stress, and $\bar{Y}_{\mathrm{p}}=$ average yield of all genotypes under optimal conditions [9].

\subsection{Artificial Intelligence Techniques}

Artificial intelligence (AI) techniques are based on the dataset for modeling and forecasting the complicated natural process and for handling the significant volumes, dynamic nature, and uncertainty of the datasets. The AI-based models are ideally suited to agricultural, hydrological, environmental, and various modeling challenges. The AI techniques are based on probability, classification, logic, statistical-learning-based approaches, various kinds of search engine optimizations, and mathematical programming. Two subsets of AI, i.e., MLP (multilayer perceptron) and SVM (support vector machine), have been widely used in the hydro-climatologic and environmental sectors. SVM is a data-mining technique [33]. It resolves classification issues by employing a flexible representation of class borders, implementing an automatic difficulty system to minimize overfitting, and locating a single global minimum in a distributed manner [34-36]. MLP is an informationprocessing technique based on a mathematical theorem and is inspired by the natural processes of the human brain and nervous system. In a typical MLP, there are multiple layers, i.e., input, output, and hidden. Each layer contains numerous neurons, which serve as the network's basic construction pieces. The input layer contains the investigated variables, whereas the output layer contains the system outputs. The hidden system handles a transfer function that trains and processes the nodes of the input parameters [23].

\subsection{Hybrid Artificial Intelligence Algorithm Based on GA (Genetic Algorithm)}

The GA is a stochastic optimization method devoid of derivatives, and it is inspired by natural selection and biological evolution. It outperforms other optimization methods in many ways. It can be used to solve issues with both continuous and discrete optimization. The GA method is less prone to getting stuck in local minima than the AI method. It is a population-inspired computational model. It is also a population genetics-inspired learning algorithm. It has primarily been utilized as a function optimizer, and that was seen to be a useful global optimization method, particularly for multi-model and non-continuous processes. Because a large amount of literature on MLP-GA and SVM-GA has already been published in previous research [37-39], we cite it only in this part. Figure 1A,B shows a schematic representation of the suggested hybrid algorithms. That model outlines a hybrid artificial intelligence (MLP and SVM) learning technique that uses the GA to optimize the network's hyperparameters. The GA tunes every network's hyperparameters by encoding them onto a lengthy chromosome. The AI technique is then utilized for training the network as a result of the GA procedure. The hybrid AI learning algorithm's process is outlined in Figure 1. 


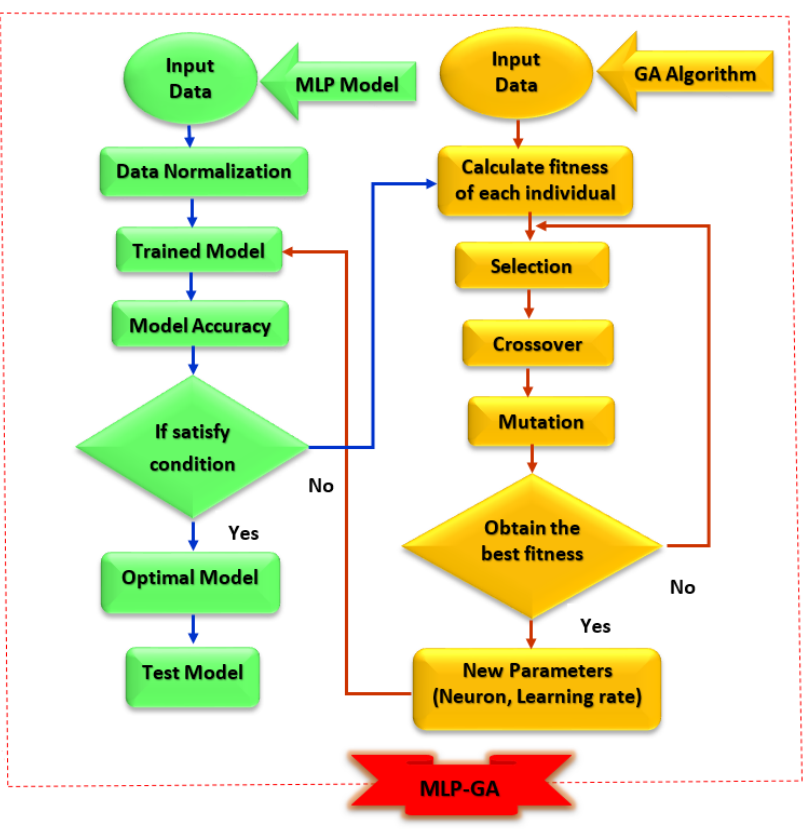

(A)

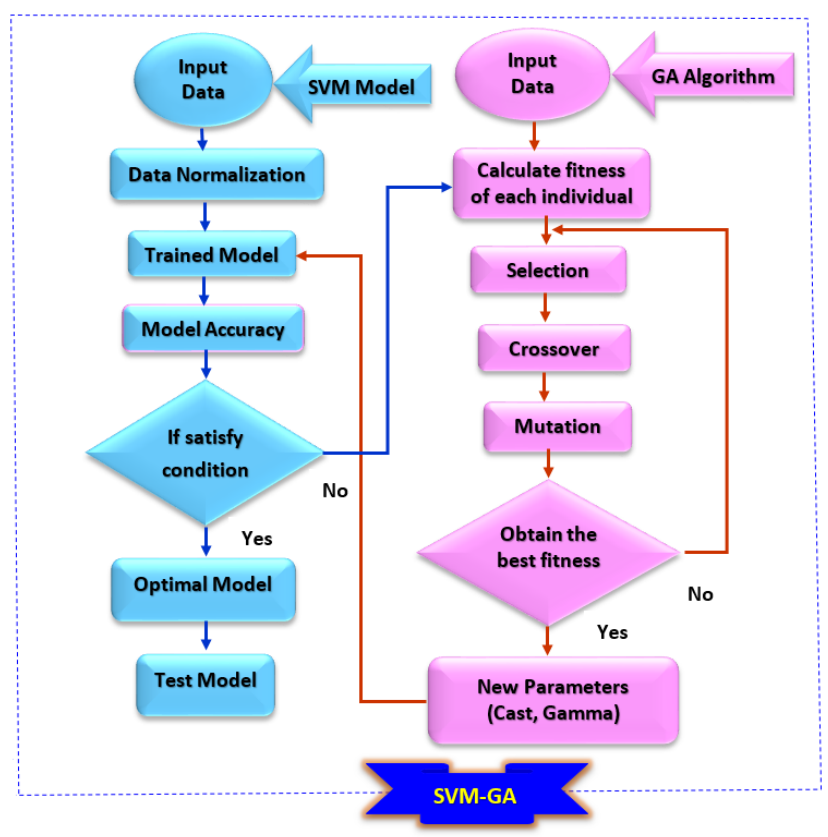

(B)

Figure 1. (A,B) flow diagram of hybrid MLP-GA and SVM-GA algorithms, respectively.

\subsection{Statistical Indices}

The performance of the developed models was evaluated based on the following indices [40].

1. Root Mean Square Error

$$
\text { RMSE }=\sqrt{\frac{\sum_{i=1}^{\mathrm{n}}\left(\mathrm{T}_{\mathrm{t}}-\mathrm{T}_{\mathrm{p}}\right)^{2}}{\mathrm{n}}}
$$

where $T_{t}$ is the observed data series, $T_{p}$ is the simulated data series, and $n$ is the number of observations.

\section{Root Mean Square Error}

$$
\mathrm{R}^{2}=\left[\frac{\mathrm{SSR}}{\mathrm{SST}}\right]
$$

where SSR is the sum of squares regression and SST is the sum of squares total.

3. Coefficient of Efficiency

$$
\mathrm{CE}=1-\frac{\sum_{\mathrm{i}=1}^{\mathrm{n}}\left(\mathrm{T}_{\mathrm{t}}-\mathrm{T}_{\mathrm{p}}\right)^{2}}{\sum_{\mathrm{i}=1}^{\mathrm{n}}\left(\mathrm{T}_{\mathrm{p}}-\overline{\mathrm{T}}_{\mathrm{p}}\right)^{2}}
$$

where $\bar{T}_{t}$ is the average of the observed data series and $\bar{Y}_{p}$ is the average of the simulated data series.

4. Willmott's Index of Agreement

$$
\mathrm{WI}=1-\frac{\sum_{\mathrm{i}=1}^{\mathrm{n}}\left(\mathrm{T}_{\mathrm{t}}-\mathrm{T}_{\mathrm{p}}\right)^{2}}{\sum_{\mathrm{i}=1}^{\mathrm{n}}\left(\left|\mathrm{T}_{\mathrm{p}}-\overline{\mathrm{T}}_{\mathrm{t}}\right|+\left|\mathrm{T}_{\mathrm{t}}-\overline{\mathrm{T}}_{\mathrm{t}}\right|\right)^{2}}
$$




\section{Results and Discussion}

\subsection{Gamma Test (GT)}

The gamma test is a non-linear relation between information (input) and yields (output) vectors based on the minimum mean squared error in the data [41]. The combined selection of relevant information and the yield vector is crucial in any modeling approach because an irrelevant information vector creates a large amount of uncertainty in the model [19]. Therefore, in the present research work, we applied GT to find an appropriate relation between yield vector, i.e., drought-tolerance index (DTI) and stress-tolerance index (STI), and information vector, i.e., days of anthesis, days of silking, days to senescence, plant height, ear length, number of kernels, and gross yield per plant. We found an applicable relation between information and yield vector based on the least values of the gradient, SE, and gamma. The number of arrangements of the information vector (days of anthesis, days of silking, days to senescence, plant height, ear length, number of kernels, and gross yield per plant) were examined to evaluate their impact on yield vector (drought-tolerance index and stress-tolerance index), for which significant amalgamations are presented in Table 1.

Table 1. Gamma test results for input variable selection.

\begin{tabular}{|c|c|c|c|c|}
\hline Model & Output/Input Combination & Gamma & Gradient & SE \\
\hline D-1 & $\mathrm{DTI}=\mathrm{f}(\mathrm{DOA}, \mathrm{DOS}, \mathrm{DTS}, \mathrm{PHt}, \mathrm{EL}, \mathrm{NK}, \mathrm{GYP})$ & 0.0085 & 0.0470 & 0.0029 \\
\hline D-2 & $\mathrm{DTI}=\mathrm{f}(\mathrm{DOA}, \mathrm{DOS}, \mathrm{DTS}, \mathrm{EL}, \mathrm{NK}, \mathrm{GYP})$ & 0.0071 & 0.0466 & 0.0020 \\
\hline D-3 & $\mathrm{DTI}=\mathrm{f}(\mathrm{DOA}, \mathrm{DOS}, \mathrm{DTS}, \mathrm{EL}, \mathrm{GYP})$ & 0.0060 & 0.0427 & 0.0045 \\
\hline D-4 & DTI = f (DOA, DOS, DTS, EL, NK, $)$ & 0.0077 & 0.0538 & 0.0021 \\
\hline D-5 & DTI = f (DOA, DTS, PHt, EL, NK, GYP $)$ & 0.0093 & 0.0468 & 0.0041 \\
\hline D-6 & $\mathrm{DTI}=\mathrm{f}(\mathrm{DOA}, \mathrm{DOS}, \mathrm{YI}, \mathrm{GYP})$ & 0.0042 & 0.0452 & 0.0016 \\
\hline D-7 & $\mathrm{STI}=\mathrm{f}(\mathrm{PHt}, \mathrm{EL}, \mathrm{NK}, \mathrm{YI}, \mathrm{GYP})$ & 0.0056 & 0.0508 & 0.0035 \\
\hline S-1 & $\mathrm{STI}=\mathrm{f}(\mathrm{DOA}, \mathrm{DOS}, \mathrm{DTS}, \mathrm{PHt}, \mathrm{EL}, \mathrm{NK}, \mathrm{GYP})$ & 0.0026 & 0.0550 & 0.0041 \\
\hline S-2 & $\mathrm{STI}=\mathrm{f}(\mathrm{DOA}, \mathrm{DOS}, \mathrm{DTS}, \mathrm{EL}, \mathrm{NK}, \mathrm{GYP})$ & 0.0071 & 0.0497 & 0.0037 \\
\hline S-3 & $\mathrm{STI}=\mathrm{f}(\mathrm{DOA}, \mathrm{DOS}, \mathrm{DTS}, \mathrm{EL}, \mathrm{GYP})$ & 0.0042 & 0.0689 & 0.0033 \\
\hline S-4 & STI = f (DOA, DOS, DTS, EL, NK, $)$ & 0.0038 & 0.0810 & 0.0027 \\
\hline S-5 & STI = f (DOA, DTS, PHt, EL, NK, GYP) & 0.0053 & 0.0791 & 0.0035 \\
\hline S-6 & $\mathrm{STI}=\mathrm{f}(\mathrm{DOA}, \mathrm{DOS}, \mathrm{YI}, \mathrm{GYP})$ & 0.0021 & 0.0434 & 0.0026 \\
\hline S-7 & $\mathrm{STI}=\mathrm{f}(\mathrm{PHt}, \mathrm{EL}, \mathrm{NK}, \mathrm{YI}, \mathrm{GYP})$ & 0.0062 & 0.0561 & 0.0037 \\
\hline
\end{tabular}

$\mathrm{DTI}=$ drought-tolerance index, DOA = day of anthesis, DOS = day of silking, DTS = day to senescence, $\mathrm{PHt}=$ plant height, EL = ear length, NK = number of kernels, GYP = gross yield per plant, YI = yield index STI = stress-tolerance index. Note: Bold values indicates best input combination, i.e., D-6 is a best input combination for drought-tolerance index (DTI), and S-6 is a best input combination for stress-tolerance index (STI).

The results of the gamma test indicated that the values of gamma, SE, and gradient varied from: 0.0042 to $0.0093,0.0452$ to 0.0538 , and 0.0016 to 0.0045 , respectively, for the DTI vector; 0.0021 to $0.0062,0.0434$ to 0.0810 , and 0.0026 to 0.0037 , respectively, for the STI vector. As a final point, the D-6 model with the arrangement of the DOA, DOS, YI, and GYP information vector was selected as the final appropriate information vector amalgamation for DTI yield, based on the least value of the gamma indices. Similarly, the S-6 model with the DOA, DOS, YI, and GYP information vector was preferred as the best information vector amalgamation for the STI yield vector, based on the least value of gamma indices. The gamma, SE, and gradient values were originated as $0.0042,0.0452$, and 0.0016 , respectively, for the D-6 model, and as 0.0021, 0.0434, and 0.0026, respectively, for the S-6 model.

\subsection{Artificial Intelligence Techniques}

In the present investigation, the two most popular artificial intelligence algorithms, namely, MLP and SVM, and their hybrids with a genetic algorithm were applied to predict drought-tolerance index and stress-tolerance index of maize. The parameters and algorithms used in the development of the AI models are given in Table 2. 
Table 2. Parameters of different AI models.

\begin{tabular}{|c|c|c|}
\hline Model & Parameters of the Algorithms for DTI & Parameters of the Algorithms for STI \\
\hline MLP & $\begin{array}{l}\text { The transfer function is tan hyperbolic; Learning rule is } \\
\text { delta bar delta; Rate of learning is } 0.2 ; \text { Number of } \\
\text { momentum values is } 0.1 \text {; Neurons in the hidden } \\
\text { layer = 19; Iteration is } 1000 ; \text { Hidden layers in the } \\
\text { structure }=1 .\end{array}$ & $\begin{array}{l}\text { The transfer function is tan hyperbolic; Learning rule is } \\
\text { delta bar delta; Rate of learning is } 0.2 \text {; Number of } \\
\text { momentum values is } 0.1 \text {; Neurons in the hidden } \\
\text { layer = 23; Iteration is } 1000 ; \text { Hidden layers in the } \\
\text { structure }=1 .\end{array}$ \\
\hline SVM & $\begin{array}{l}\text { SVM type: regression; Kernel function: Radial; } \\
\text { Cast: 11; Gamma: 0.25. }\end{array}$ & $\begin{array}{c}\text { SVM type: regression; Kernel function: Radial; } \\
\text { Cast: } 13 \text {; Gamma: } 0.25 .\end{array}$ \\
\hline MLP-GA & $\begin{array}{l}\text { GA (Population size: } 30 \text {; Generation: } 100 \text {; Crossover: } 0.9 \text {; } \\
\text { Mutation: } 0.001 \text { ). } \\
\text { MLP (Rate of learning is } 0.2 ; \text { Number of momentum } \\
\text { values is 0.1; Neurons in the hidden layer }=32 \text {; Iteration } \\
\text { is } 1000 ; \text { Hidden layers in the structure }=1 \text { ). }\end{array}$ & $\begin{array}{l}\text { GA (Population size: 32; Generation: } 100 \text {; Crossover: 0.9; } \\
\text { Mutation: } 0.001 \text { ). } \\
\text { MLP (Rate of learning is 0.2; Number of momentum } \\
\text { values is } 0.1 \text {; Neurons in the hidden layer }=51 \text {; Iteration } \\
\text { is } 1000 ; \text { Hidden layers in the structure }=1 \text { ). }\end{array}$ \\
\hline SVM-GA & $\begin{array}{l}\text { GA (Population size: 30; Generation: 100; Crossover: } \\
\text { 0.90; Mutation: 0.001). } \\
\text { SVM (Kernel function: Radial; Cast: 31; Gamma: 0.1). }\end{array}$ & $\begin{array}{l}\text { GA (Population size: 40; Generation: 100; Crossover: } \\
\text { 0.90; Mutation: 0.001). } \\
\text { SVM (Kernel function: Radial; Cast: 18; Gamma: 0.1). }\end{array}$ \\
\hline
\end{tabular}

Based on the tan hyperbolic function and the delta bar delta learning rule, the alone MLP model was developed, whereas, in the hybrid MLP-GA model, the hyperparameters such as learning rate, the neurons in the layer, and a hidden layer of the MLP model were found based on a genetic algorithm. Similarly, the alone SVM model was developed through a radial function, while in the hybrid SVM-GA model, hyperparameters such as cast and gamma were optimized using a genetic algorithm. The hybrid models were ignored due to the overfitting problems of the alone MLP and SVM models. It is observed that the ML model was found to show the best results for learning rate (0.2), momentum (0.1), neurons (19), and hidden layers (1); as a result, the architecture of the best MLP model was (4-19-1), where the first layer (4), the second layer (19), and the third layer (1) are the information vectors (DOA, DOS, NK, and GYP), the neuron in the hidden layer, and the yield vector (DTI), respectively. Moreover, the architecture of the best MLP model was 3-23-1 to predict the STI. The best architecture of the SVM model was 3-C11-1 and 3-C13-1, respectively, for DTI and STI prediction. The novel MLP-GA hybrid model was found to have the best architecture (4-32-1) at population size (30), generation (100), crossover (0.9), and mutation (0.001) for the prediction of DTI in maize, while the best architecture was (4-51-1) at population size (32), generation (100), crossover (0.9), and mutation (0.001) for the prediction of STI in maize. Correspondingly, the best architecture of the SVM-GA models was 3-C31-1 and 3-C18-1, respectively, to simulate the DTI and STI of maize.

The performances of the developed MLP, SVM, MLP-GA, and SVM-GA models were examined based on least values of error, i.e., RMSE ( 0 values show perfect prediction and $+\infty$ show poor prediction) and the largest values of NSE (values close to 1 point out good performance and 0 for poor performance), $R^{2}$ ( 1 for perfect correlation and 0 for no correlation), and WI ( 1 for perfect agreement and 0 to no agreement). The models were also assessed based on an optical observation based on a line diagram, scatter plot, Taylor diagram, and discrepancy ratio scatter plot. The Taylor diagram was provided by three different indices, i.e., RMSE, correlation of coefficient, and standard deviation on the single visual platform for the companion of the various models. All of the information and yield data were fragmented into two groups. The first group was applied for training purposes (to calibrate the model and find model parameters) and the second group was applied for testing purposes (to validate the developed model).

The results of the MLP model, which is obtainable in Table 3, show that the values of RMSE, $\mathrm{R}^{2}$, NSE, and WI during the training period were found to be $0.041,0.839,0.836$, and 0.946 , respectively. During the testing, the period was $0.025,0.839,0.799$, and 0.932 , respectively, for the prediction of the DTI. Additionally, the SVM model had values of RMSE (0.038), $R^{2}(0.855)$, NSE (0.855), and WI (0.957) during the training period, and the 
RMSE, $\mathrm{R}^{2}$, NSE, and WI were $0.023,0.886,0.830$, and 0.936 , respectively, during the testing period for the DTI.

Table 3. Results of different AI models for drought-tolerance index.

\begin{tabular}{ccccccccc}
\hline \multirow{2}{*}{ Model } & \multicolumn{4}{c}{ Training } & \multicolumn{3}{c}{ Testing } \\
\cline { 2 - 10 } & RMSE & R2 & NSE & WI & RMSE & R2 & NSE & WI \\
\hline MLP & 0.041 & 0.839 & 0.836 & 0.946 & 0.025 & 0.839 & 0.799 & 0.932 \\
SVM & 0.038 & 0.855 & 0.855 & 0.957 & 0.023 & 0.886 & 0.830 & 0.936 \\
MLP-GA & 0.028 & 0.921 & 0.921 & 0.978 & 0.020 & 0.910 & 0.890 & 0.964 \\
SVM-GA & 0.013 & 0.984 & 0.984 & 0.996 & 0.018 & 0.916 & 0.892 & 0.966 \\
\hline
\end{tabular}

In this study, the hybrid of MLP with a genetic algorithm (GA) was used to check the hybrid efficiency. In the MLP-GA model, the best values of RMSE $(0.013), \mathrm{R}^{2}(0.921)$, NSE (0.921), and WI (0.978) were found for the period of training; for the testing period, these values were $0.020,0.910,0.890$, and 0.964 , respectively. Another hybrid of a support vector machine with a genetic algorithm (SVM-GA) was used to predict the DTI of maize crops. In the SVM-GA model, the best values of RMSE, ${ }^{2}$, NSE, and WI were $0.018,0.984,0.984$, and 0.996, respectively, for the training period, and RMSE (0.018), $R^{2}(0.916)$, NSE (0.992), and WI (0.966) for the testing period. After comparing the results of MLP, SVM, and their hybrid models based on algebraic indices, it was reflected that the overall performance of the artificial intelligence techniques was very good for the DTI prediction of maize. In addition, the MLP model has poor performance compared to the SVM model for the prediction of the DTI. It also exhibited that genetic-based hybrid models, i.e., MLP-GA and SVM-GA models, have better performance than the alone MLP and SVM models during the training and testing periods for the DTI prediction of maize.

In the present research, a stress-tolerance index (STI) was predicted based on MLP, SVM, and their hybrid with a genetic algorithm. In the MLP and SVM models, a trialand-error approach was used to find the hyperparameters of MLP and SVM models, while MLP-GA and SVM-GA models were applied to genetic algorithms to optimize the hyperparameters of the MLP and SVM models. The quantitative results of the MLP, SVM, MLP-GA, and SVM-GA models, which are presented in Table 4, show that the best RMSE values were found to be $0.044,0.044,0.037$, and 0.018 , respectively, for the MLP, SVM, MLP-GA, and SVM-GA models during training time, and 0.023, 0.017, 0.015, and 0.009, respectively, for the MLP, SVM, MLP-GA, and SVM-GA models during the testing time; the $\mathrm{R}^{2}$ values were found to be $0.824,0.826,0.885$, and 0.972 during the training phase, and $0.884,0.919,0.944$, and 0.978 during the testing phase for the MLP, SVM, MLP-GA, and SVM-GA models, respectively; the maximum NSE values were $0.824,0.826,0.878$, and 0.970 during the training period and $0.815,0.898,0.928$, and 0.973 during the testing period for the MLP, SVM, MLP-GA, and SVM-GA models, respectively; the best WI values were found to be $0.946,0.946,0.959$, and 0.991, respectively, for the MLP, SVM, MLP-GA, and SVM-GA models during the training time, and $0.933,0.976,0.982$, and 0.992 , respectively, for the MLP, SVM, MLP-GA, and SVM-GA models during the testing time.

Table 4. Results of MLP and different AI models for stress-tolerance index.

\begin{tabular}{ccccccccc}
\hline \multirow{2}{*}{ Model } & \multicolumn{4}{c}{ Training } & \multicolumn{3}{c}{ Testing } \\
\cline { 2 - 9 } & RMSE & R2 & NSE & WI & RMSE & R2 & NSE & WI \\
\hline MLP & 0.044 & 0.824 & 0.824 & 0.946 & 0.023 & 0.884 & 0.815 & 0.933 \\
SVM & 0.044 & 0.826 & 0.826 & 0.946 & 0.017 & 0.919 & 0.898 & 0.976 \\
MLP-GA & 0.037 & 0.885 & 0.878 & 0.959 & 0.015 & 0.944 & 0.928 & 0.982 \\
SVM-GA & 0.018 & 0.972 & 0.970 & 0.991 & 0.009 & 0.978 & 0.973 & 0.992 \\
\hline
\end{tabular}


After comparing the performance of the MLP, SVM, MLP-GA, and SVM-GA models, it can be concluded that the performance of all the developed models was very good based on the statistical indices [42]. The MLP model has poor performance compared to the SVM model for predicting the stress-tolerance index (STI) in maize plants. Moreover, the novel hybrid models based on genetic algorithms have better performance than the MLP and SVM models alone. The MLP-GA model has low performance compared to the SVM-GA model, whereas it exhibited better performance than the MLP and SVM models. The SVM-GA model has the best performance to all applied models to predict the stress-tolerance index (STI) in maize plants. Therefore, the SVM-GA model (4-C18-1) can be used in the future to predict the stress-tolerance index (STI). Similar results for the MLP and SVM models, as well as the genetic algorithm-based MLP and SVM models, were found by many researchers. Akram and Fatemeh [37] assessed the capability of different optimization algorithms for the simulation of daily evaporation. The results showed that the performance of the hybrid models was superior to other models. Stamenković [43] used the MLP and SVM model to simulate phosphate and nitrate in surface water. The performance of both models was good for predicting the water quality of surface water. Rahgoshay et al. [44] studied suspended sediment concentration using SVM and SVM-GA models. It was suggested that the performance of the SVM was improved after applying a genetic algorithm for the prediction of suspended sediment concentration. Massah et al. [45] used SVM and hybrid SVM models to predict the yield of kiwifruit. The results indicated that the potential of the SVM improved with a hybrid algorithm for the prediction of the yield of kiwifruit.

The performance of the developed MLP, SVM, MLP-GA, and SVM-GA models was also evaluated based on a qualitative assessment. The qualitative assessment was done by the visual observation of line diagrams, scatter plots, Taylor diagrams, and discrepancy ratio scatter plots. The line diagram indicated, from Figures 2 and 3, that the droughttolerance index (DTI) predicted by the MLP and SVM models slightly deviates from the observed drought-tolerance index. In contrast, the drought-tolerance index predicted by the MLP-GA and SVM-GA models was similar to the observed predicted drought-tolerance index. Similarly, scatter plots showed that the drought-tolerance index values predicted by the MLP and SVM models were deviated from the 1:1 $(\mathrm{X}=\mathrm{Y})$ line, but the drought-tolerance index values predicted by the MLP-GA and SVM-GA models showed fewer deviations. It was also depicted, from Figures 4 and 5 (Taylor diagram during training and testing periods), that the MLP and SVM models have higher RMSE and standard deviation from the observed and low correlation coefficient than the novel hybrid models. The discrepancy ratio value ranges from -1 to 1 ; the minus value indicates under prediction, the plus value shows over prediction, and the zero discrepancy ratio indicates perfect prediction by the models $[10,19]$. In the same way, it was observed, from Figures 6 and 7, that the MLP and SVM models had a high deviation of discrepancy ratio value from zero, compared to the hybrid MLP-GA and SVM-GA models. 

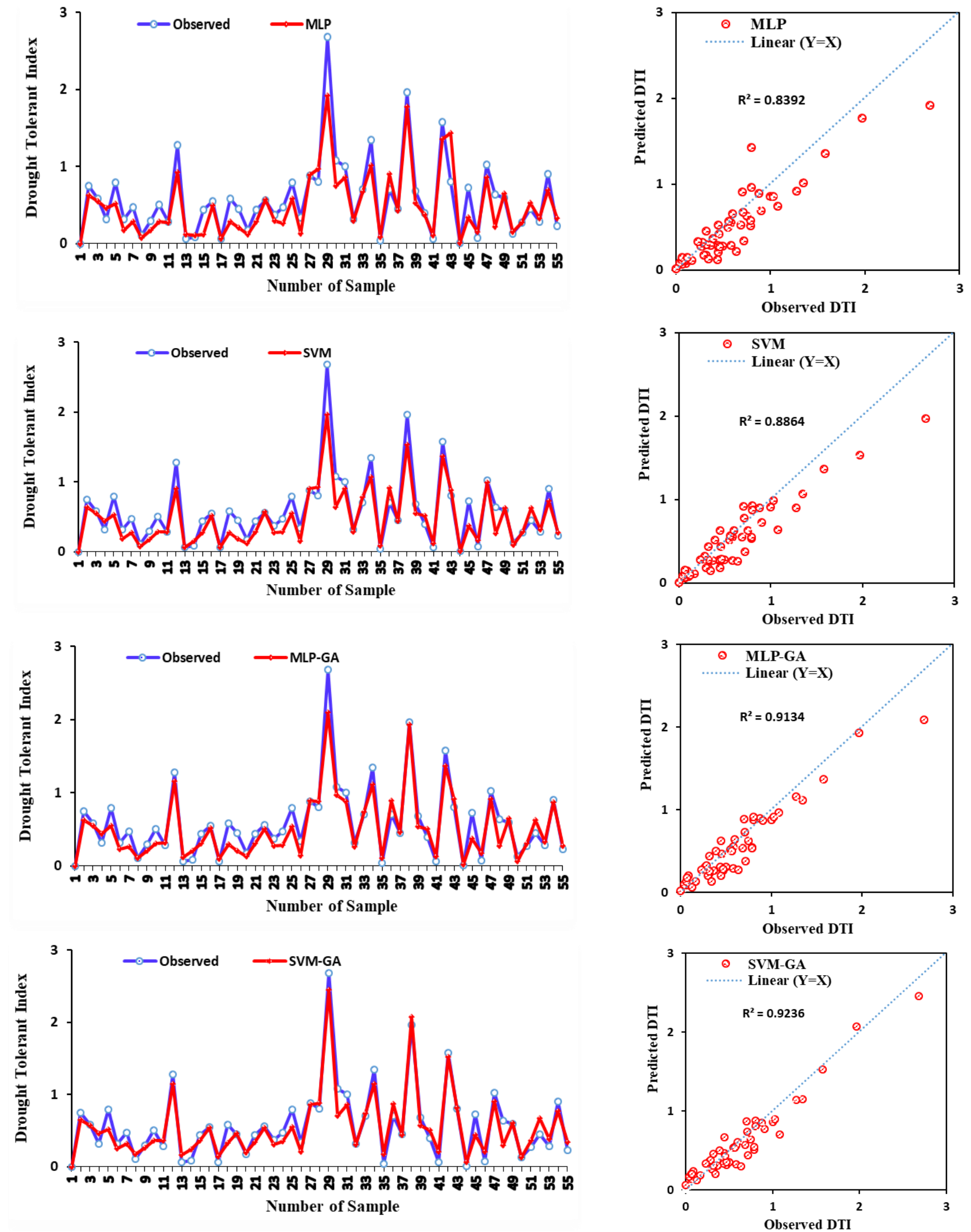

Figure 2. Line and scatter diagram of different artificial intelligence techniques for droughttolerance index. 

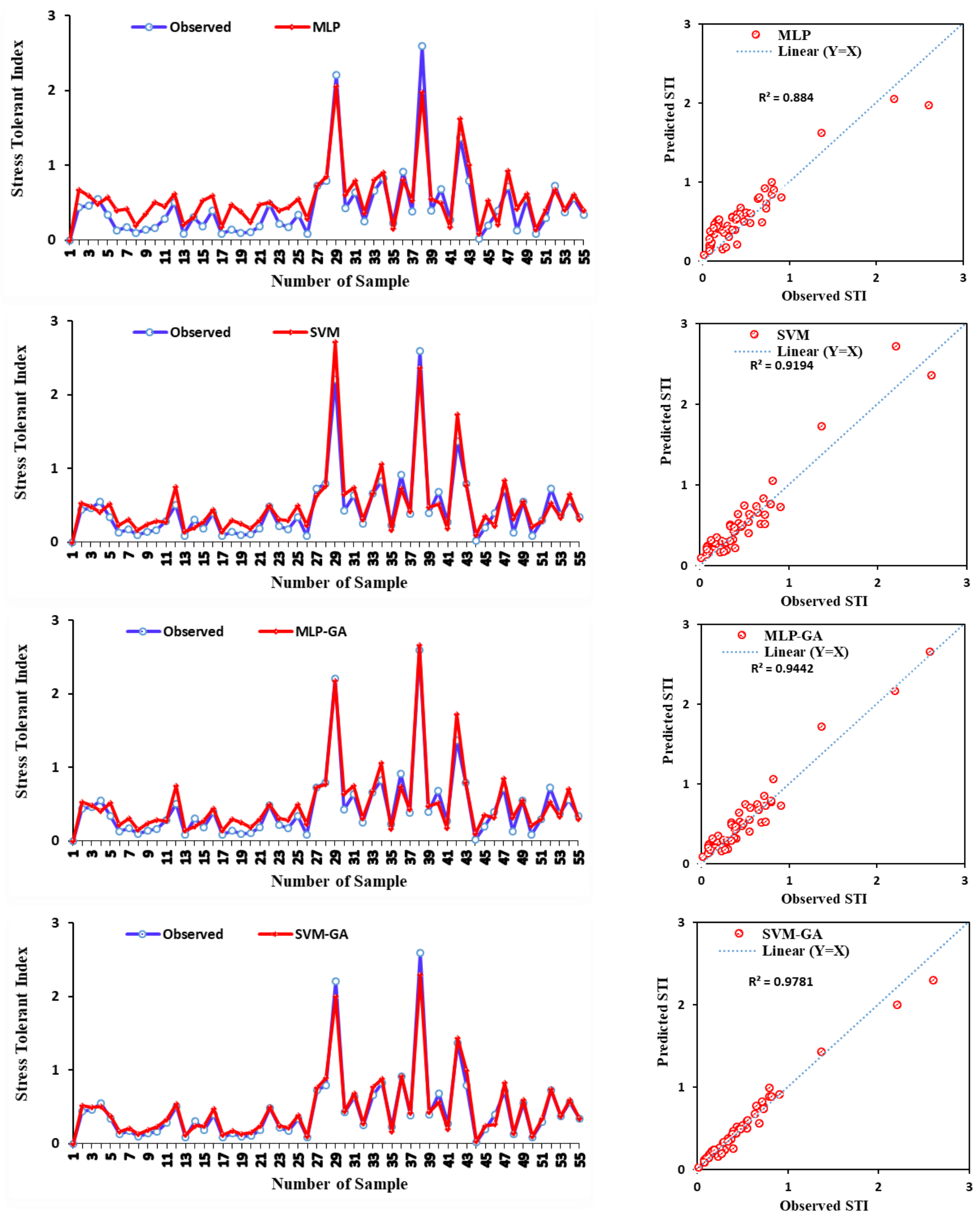

Figure 3. Line and scatter diagram of different artificial intelligence techniques for stresstolerance index. 

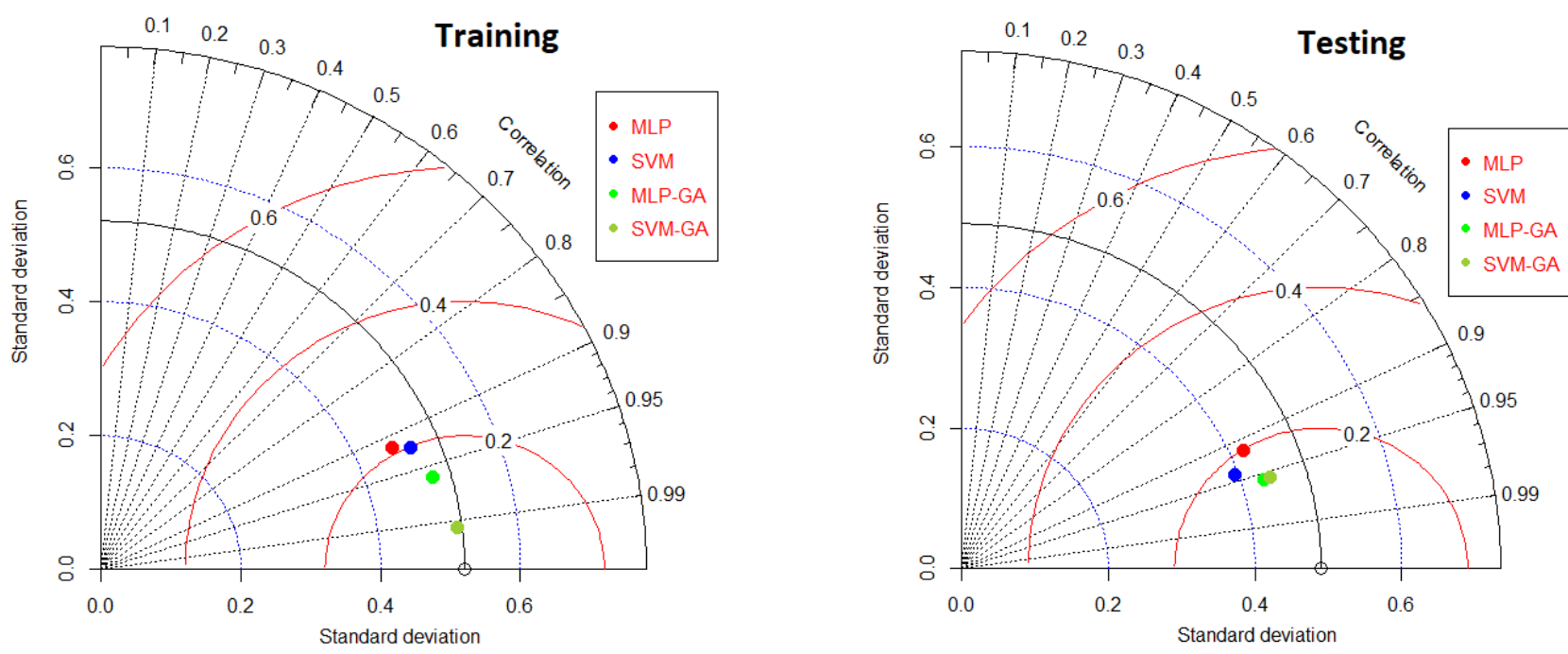

Figure 4. Taylor diagram of different artificial intelligence techniques for drought-tolerance index.
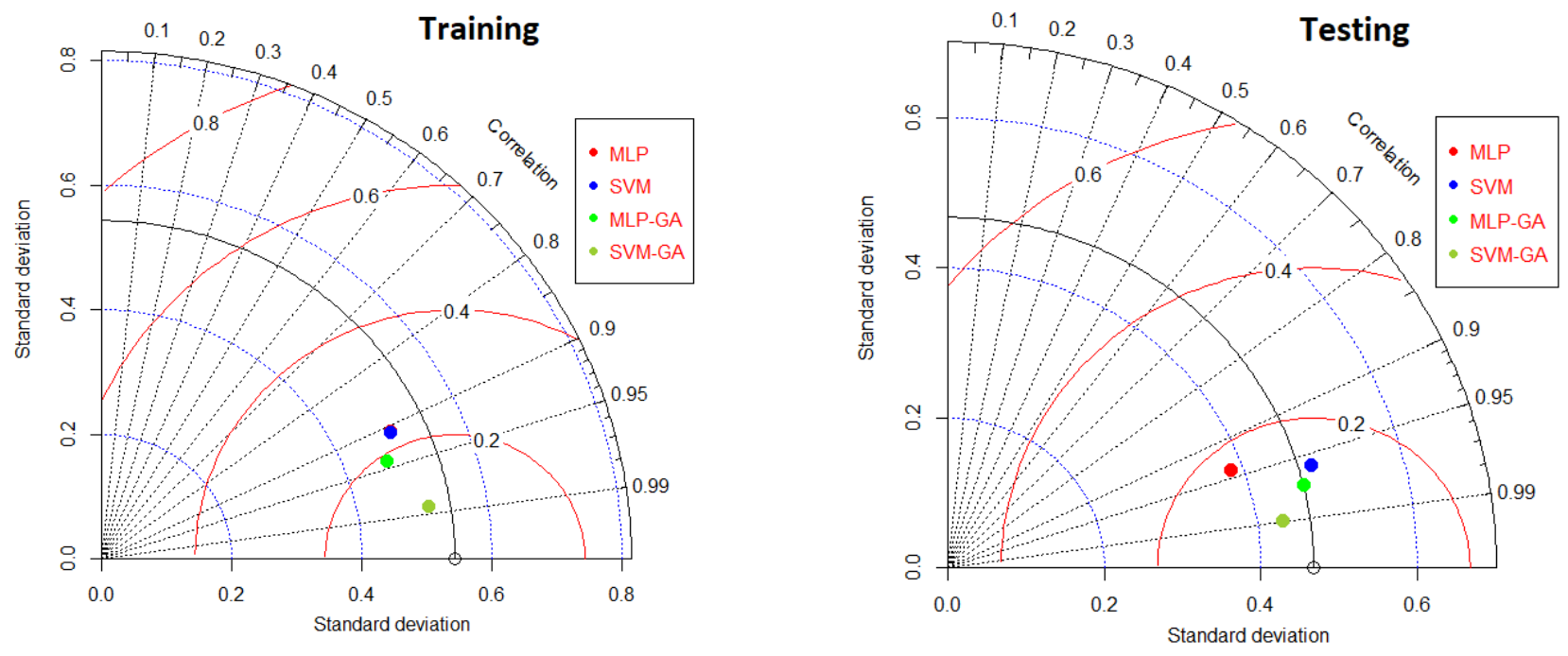

Figure 5. Taylor diagram of different artificial intelligence techniques for stress-tolerance index.
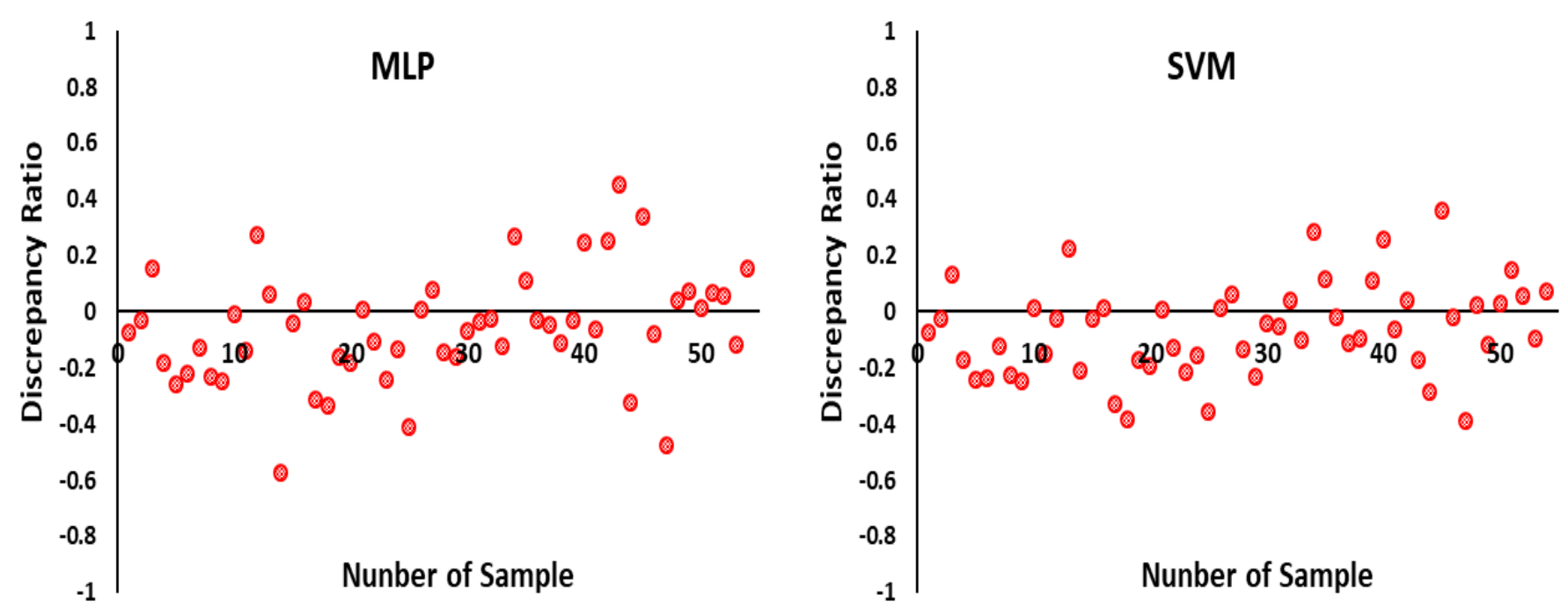

Figure 6. Cont. 

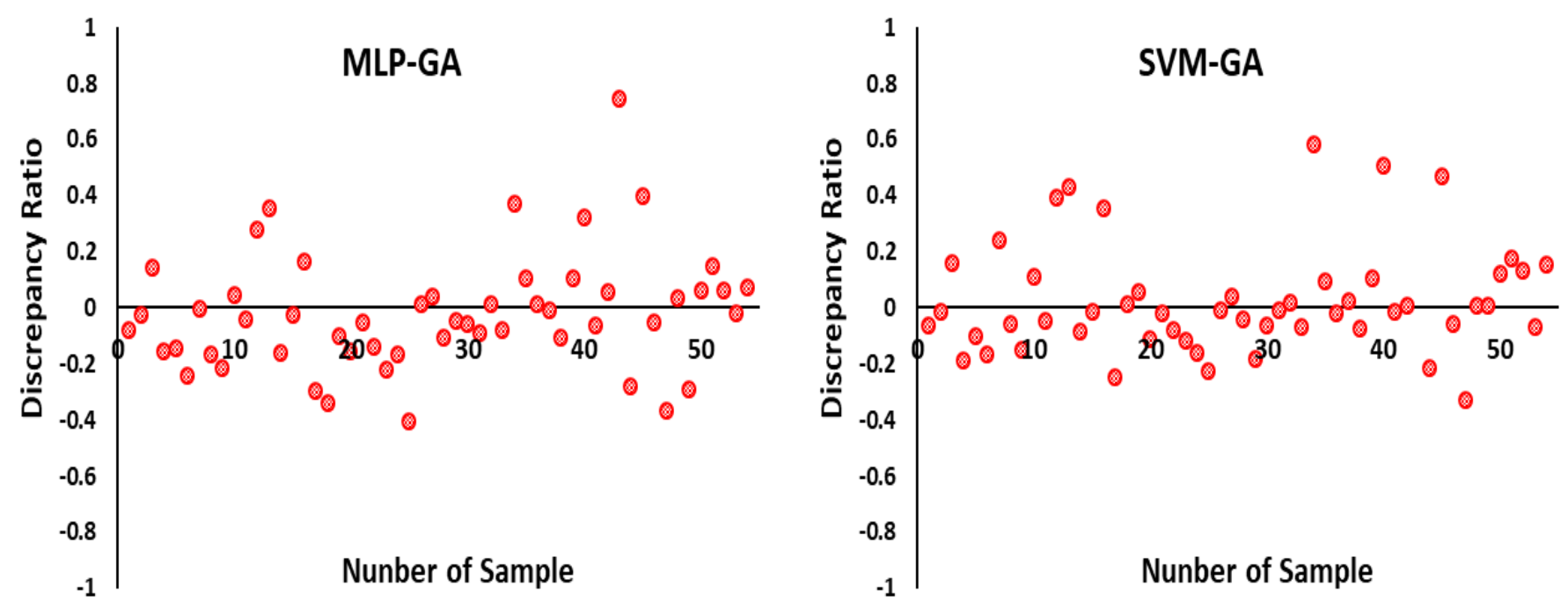

Figure 6. Discrepancy ratio scatter plot of different artificial intelligence techniques for droughttolerance index.
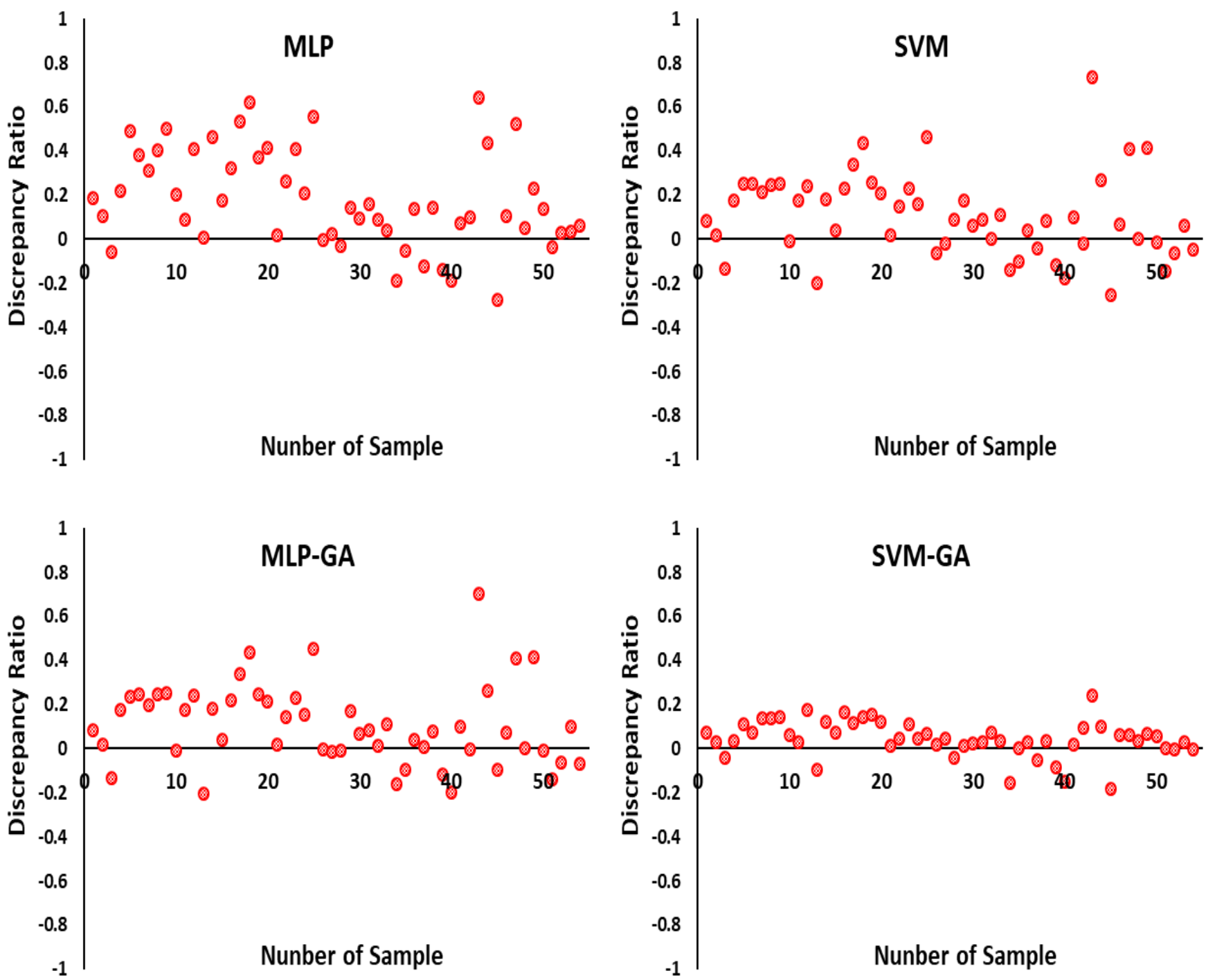

Figure 7. Discrepancy ratio scatter plot of different artificial intelligence techniques for stresstolerance index. 
Overall, a visual interpretation indicates that the SVM-GA model predicted the drought-tolerance index and stress-tolerance index more accurately than the other models. From Figure 8, the surface 3D diagram plots of the drought-tolerance index and the stress-tolerance index, with yield index and gross yield production, indicated that the drought-tolerance index and stress-tolerance index surface 3D plots of the observed and predicted results were similar to each other.
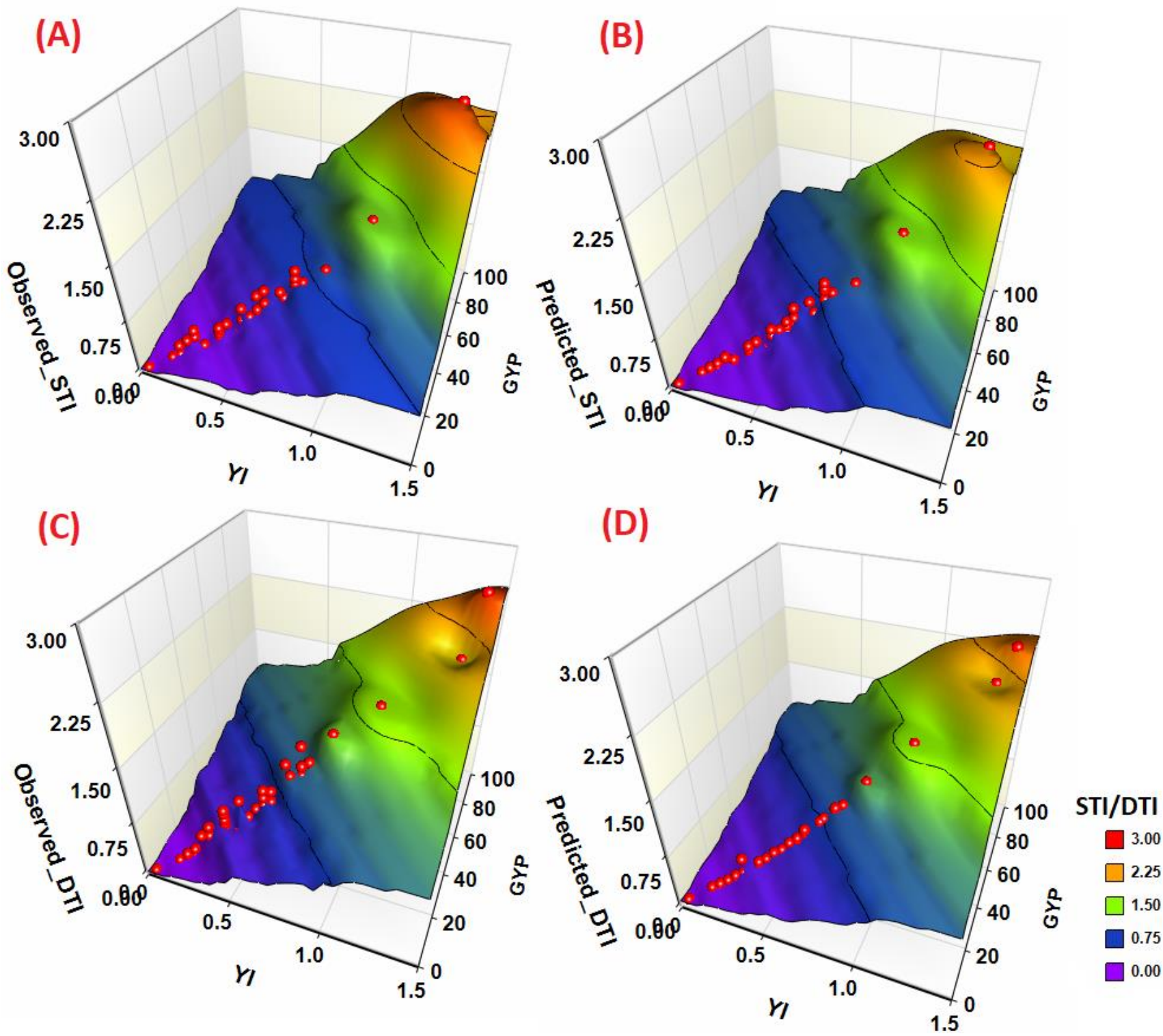

Figure 8. Surface 3D plots of stress-tolerance index and drought-tolerance index, with yield index and gross yield production, for observed STI (A), predicted STI (B), observed DTI (C), and predicted DTI (D), respectively.

In addition, it was concluded that the drought-tolerance index and the stress-tolerance index increased with increasing yield index and gross yield production values. This research reflected that this can be considered a solution to predict agricultural drought concerning maize crops. To decide on strategies regarding drought, the monitoring of drought is an essential element that will provide us with early warnings of drought. National food security is the priority of any nation, and for that, the prediction of drought will help the agricultural sector with the better management of droughts. The loss in crop production of crops such as maize due to drought can depend on the intensity of the drought, its duration, 
and most importantly, the growth stages of crop plants. This novel hybrid model will help with predicting drought in maize crops and will give information that might be helpful for farmers to avoid or minimize production losses. The novel hybrid model is prepared based on data input of teosinte-introgressed maize lines.

The novel hybrid model will help assess and develop drought-tolerant varieties by predicting drought- and stress-tolerance indices. Therefore, plant breeders will be able to evaluate the genetic worth of the genotypes. This will fulfil the prime goal of a farmer, i.e., the development of such varieties that will grow in a wide range of climatic conditions. This drought- and stress-tolerance indices-predicting model will assist with identifying and selecting highly stable and high-yielding genotypes under drought conditions. The combination of drought- and stress-tolerance indices may be a more valuable selection criteria for improving drought tolerance.

\section{Conclusions}

Drought tolerance and stress-tolerance indices are important tools for identifying the level of tolerance in a genotype. It was indicated from gamma test results that the arrangement of DOA, DOS, YI, and GYP information vectors was selected as the final appropriate information vector amalgamation for DTI yield, based on the least value of the gamma indices. Similarly, DOA, DOS, YI, and GYP information vectors were preferred as the best information vector amalgamation for STI yield vector, based on the least value of the gamma indices. Based on statistical indices and visual interpretation, it was concluded that results of the MLP, SVM, MLP-GA, and SVM-GA algorithms have a satisfactorily predict the drought-tolerance index and stress-tolerance index in maize crop. It also appeared that the genetic algorithm-based hybrid models (MLP-GA and SVM-GA) were better able to predict the the drought-tolerance index and stress-tolerance index in maize crops. Similarly, the SVM-GA model had the highest potential to forecast the DTI and STI in maize crops, compared to the MLP, SVM, and MLP-GA models. After analyzing the results of the MLP, SVM, MLP-GA, and SVM-GA algorithms, it can be said that artificial intelligence-based algorithms can be used for the prediction of drought-tolerance and stress-tolerance indices in maize crops. It is also suggested that artificial intelligence-based algorithms can be used in the future for forecasting drought-tolerance and stress-tolerance indices in different crops. The effect of drought on crop production can be evaluated through crop models. These models are nothing but mathematical equations that give information about the relationships between crop growth, production, management technology, and climatic conditions. The present research represents the use of a novel hybrid model for predicting a drought-tolerance index and a stress-tolerance index to assess the effect of drought on maize yield loss, and this model will be very helpful for researchers and policymakers.

Author Contributions: Conceptualization, V.K.S., D.K.V. and B.S.; methodology, V.K.S.; software, V.K.S. and D.K.V.; validation, A.K.; formal analysis, A.K., V.P.S. and B.S.; investigation, N.K.S.; resources, N.K.S.; data curation, V.P.S.; writing-original draft preparation, V.K.S., S.A., B.S., A.J., N.A.-A. and A.K.; writing-review and editing, V.P.S., N.K.S. and N.A.-A.; visualization, V.K.S., N.A.-A. and D.K.V.; supervision, V.P.S. and N.K.S.; project administration, V.K.S. and N.K.S.; funding acquisition, N.A.-A. All authors have read and agreed to the published version of the manuscript.

Funding: This research received no external funding.

Institutional Review Board Statement: Not applicable.

Informed Consent Statement: Not applicable.

Data Availability Statement: Not applicable.

Acknowledgments: We acknowledge the Director of the Experiment Station and the Head of the Department of Genetics and Plant Breeding at the Govind Ballabh Pant University of Agriculture and Technology, Pantnagar, for proving experimental facilities.

Conflicts of Interest: The authors declare no conflict of interest. 


\section{References}

1. Kumar, A.; Singh, N.K.; Adhikari, S.; Joshi, A. Morphological and molecular characterization of teosinte derived maize population. Indian J. Genet. Plant Breed. 2019, 79, 670-677. [CrossRef]

2. Alahdadi, I.; Oraki, H.; Khajani, F.P. Effect of water stress on yield and yield components of sunflower hybrids. Afr. J. Biotechnol. 2011, 10, 6504-6509. [CrossRef]

3. Golbashy, M.; Ebrahimi, M.; Khorasani, S.K.; Choukan, R. Evaluation of drought tolerance of some corn (Zea mays L.) hybrids in Iran. Afr. J. Agric. Res. 2010, 5, 2714-2719. [CrossRef]

4. FAO Crop Water Information: Maize. Available online: http://www.fao.org/nr/water/cropinfo-maize.html (accessed on 30 January 2022).

5. Passioura, J.B. Roots and drought resistance. In Developments in Agricultural and Managed Forest Ecology; Elsevier: Amsterdam, The Netherlands, 1983; Volume 12, pp. 265-280. ISBN 0166-2287.

6. Messmer, R.E. The Genetic Dissection of Key Factors Involved in the Drought Tolerance of Tropical Maize (Zea mays L.). Ph.D. Thesis, ETH, Zurich, Switzerland, 2006.

7. Fischer, R.A.; Maurer, R. Drought resistance in spring wheat cultivars. I. Grain yield responses. Aust. J. Agric. Res. 1978, 29, 897-912. [CrossRef]

8. Ghorbani, M.A.; Shamshirband, S.; Haghi, D.Z.; Azani, A.; Bonakdari, H.; Ebtehaj, I. Application of firefly algorithm-based support vector machines for prediction of field capacity and permanent wilting point. Soil Tillage Res. 2017, 172, 32-38. [CrossRef]

9. Kim, S.; Singh, V.P. Modeling daily soil temperature using data-driven models and spatial distribution. Theor. Appl. Climatol. 2014, 118, 465-479. [CrossRef]

10. Singh, V.K.; Singh, B.P.; Kisi, O.; Kushwaha, D.P. Spatial and multi-depth temporal soil temperature assessment by assimilating satellite imagery, artificial intelligence and regression based models in arid area. Comput. Electron. Agric. 2018, 150, 205-219. [CrossRef]

11. Gu, Z.; Zhu, T.; Jiao, X.; Xu, J.; Qi, Z. Neural network soil moisture model for irrigation scheduling. Comput. Electron. Agric. 2021, 180, 105801. [CrossRef]

12. Bhagwat, S.; Kashyap, P.S.; Singh, B.P.; Singh, V.K. Daily pan evaporation modeling in hilly region of Uttarakhand using artificial neural network. Indian J. Ecol. 2017, 44, 467-473.

13. Keshtegar, B.; Piri, J.; Kisi, O. A nonlinear mathematical modeling of daily pan evaporation based on conjugate gradient method. Comput. Electron. Agric. 2016, 127, 120-130. [CrossRef]

14. Khosravi, K.; Daggupati, P.; Alami, M.T.; Awadh, S.M.; Ghareb, M.I.; Panahi, M.; Pham, B.T.; Rezaie, F.; Qi, C.; Yaseen, Z.M Meteorological data mining and hybrid data-intelligence models for reference evaporation simulation: A case study in Iraq Comput. Electron. Agric. 2019, 167, 105041. [CrossRef]

15. Kushwaha, N.L.; Rajput, J.; Elbeltagi, A.; Elnaggar, A.Y.; Sena, D.R.; Vishwakarma, D.K.; Mani, I.; Hussein, E.E. Data Intelligence Model and Meta-Heuristic Algorithms-Based Pan Evaporation Modelling in Two Different Agro-Climatic Zones: A Case Study from Northern India. Atmosphere 2021, 12, 1654. [CrossRef]

16. Ramdas, S.; Singh, R.; Sharma, I. Exploring the performance of wheat production in India. J. Wheat Res. 2020, 4, 37-44.

17. Sihag, P.; Tiwari, N.K.; Ranjan, S. Prediction of unsaturated hydraulic conductivity using adaptive neuro-fuzzy inference system (ANFIS). ISH J. Hydraul. Eng. 2019, 25, 132-142. [CrossRef]

18. Tang, D.; Feng, Y.; Gong, D.; Hao, W.; Cui, N. Evaluation of artificial intelligence models for actual crop evapotranspiration modeling in mulched and non-mulched maize croplands. Comput. Electron. Agric. 2018, 152, 375-384. [CrossRef]

19. Singh, V.K.; Kumar, D.; Kashyap, P.S.; Kisi, O. Simulation of suspended sediment based on gamma test, heuristic, and regressionbased techniques. Environ. Earth Sci. 2018, 77, 708. [CrossRef]

20. Citakoglu, H. Comparison of artificial intelligence techniques via empirical equations for prediction of solar radiation. Comput Electron. Agric. 2015, 118, 28-37. [CrossRef]

21. Esmaeilbeiki, F.; Nikpour, M.R.; Singh, V.K.; Kisi, O.; Sihag, P.; Sanikhani, H. Exploring the application of soft computing techniques for spatial evaluation of groundwater quality variables. J. Clean. Prod. 2020, 276, 124206. [CrossRef]

22. Shukla, R.; Kumar, P.; Vishwakarma, D.K.; Ali, R.; Kumar, R.; Kuriqi, A. Modeling of stage-discharge using back propagation ANN-, ANFIS-, and WANN-based computing techniques. Theor. Appl. Climatol. 2021, 147, 867-889. [CrossRef]

23. Singh, V.K.; Singh, B.P.; Kumar, A. A Comparative Study of Artificial Intelligence and Conventional Techniques for Rainfall-Runoff Modeling. Int. J. Agric. Eng. 2017, 10, 441-449. [CrossRef]

24. Ryabchuk, N.; Grishko, N.; Grishko, V.; Rudenko, A.; Petryk, V.; Bapiyev, I.; Fedushko, S. Artificial Intelligence Technologies Using in Social Engineering Attacks. In Proceedings of the International Workshop on Cyber Hygiene (CybHyg-2019) [CEUR Workshop Proceedings], Kyiv, Ukraine, 30 November 2020; Volume 2654, pp. 546-555.

25. Tahir, N.M.T.; Ausat, A.N.; Bature, U.I.; Abubakar, K.A.; Gambo, I. Off-line Handwritten Signature Verification System: Artificial Neural Network Approach. Int. J. Intell. Syst. Appl. 2021, 13, 45-57. [CrossRef]

26. Singh, V.K.; Kumar, P.; Singh, B.P.; Malik, A. A comparative study of adaptive neuro fuzzy inference system (ANFIS) and multiple linear regression (MLR) for rainfall-runoff modelling. Int. J. Nat. Sci. 2016, 7, 714-723.

27. Singh, V.K.; Kumar, P.; Singh, B.P. Rainfall-runoff modeling using artificial neural networks (ANNs) and multiple linear regression (MLR) techniques. Indian J. Ecol. 2016, 43, 436-442. 
28. Darbandi, S.; Pourhosseini, F.A. River flow simulation using a multilayer perceptron-firefly algorithm model. Appl. Water Sci. 2018, 8, 85. [CrossRef]

29. Heddam, S.; Sanikhani, H.; Kisi, O. Application of artificial intelligence to estimate phycocyanin pigment concentration using water quality data: A comparative study. Appl. Water Sci. 2019, 9, 164. [CrossRef]

30. de Oliveira, M.F.; dos Santos, A.F.; Kazama, E.H.; de Souza Rolim, G.; da Silva, R.P. Determination of application volume for coffee plantations using artificial neural networks and remote sensing. Comput. Electron. Agric. 2021, 184, 106096. [CrossRef]

31. Özger, M.; Başakın, E.E.; Ekmekcioğlu, Ö.; Hacısüleyman, V. Comparison of wavelet and empirical mode decomposition hybrid models in drought prediction. Comput. Electron. Agric. 2020, 179, 105851. [CrossRef]

32. Sayari, S.; Mahdavi-Meymand, A.; Zounemat-Kermani, M. Irrigation water infiltration modeling using machine learning. Comput. Electron. Agric. 2021, 180, 105921. [CrossRef]

33. Tabari, H.; Kisi, O.; Ezani, A.; Talaee, P.H. SVM, ANFIS, regression and climate based models for reference evapotranspiration modeling using limited climatic data in a semi-arid highland environment. J. Hydrol. 2012, 444, 78-89. [CrossRef]

34. Tabari, H.; Martinez, C.; Ezani, A.; Hosseinzadeh Talaee, P. Applicability of support vector machines and adaptive neurofuzzy inference system for modeling potato crop evapotranspiration. Irrig. Sci. 2013, 31, 575-588. [CrossRef]

35. Wen, X.; Si, J.; He, Z.; Wu, J.; Shao, H.; Yu, H. Support-Vector-Machine-Based Models for Modeling Daily Reference Evapotranspiration with Limited Climatic Data in Extreme Arid Regions. Water Resour. Manag. 2015, 29, 3195-3209. [CrossRef]

36. Shiri, J.; Nazemi, A.H.; Sadraddini, A.A.; Landeras, G.; Kisi, O.; Fakheri Fard, A.; Marti, P. Comparison of heuristic and empirical approaches for estimating reference evapotranspiration from limited inputs in Iran. Comput. Electron. Agric. 2014, 108, 230-241. [CrossRef]

37. Seifi, A.; Soroush, F. Pan evaporation estimation and derivation of explicit optimized equations by novel hybrid meta-heuristic ANN based methods in different climates of Iran. Comput. Electron. Agric. 2020, 173, 105418. [CrossRef]

38. Oh, M.S.; Chen, Z.; Jahanshiri, E.; Isa, D.; Wong, Y.W. An economic feasibility assessment framework for underutilised crops using Support Vector Machine. Comput. Electron. Agric. 2020, 168, 105116. [CrossRef]

39. Pourmohammadali, B.; Salehi, M.H.; Hosseinifard, S.J.; Boroujeni, I.E.; Shirani, H. Studying the relationships between nutrients in pistachio leaves and its yield using hybrid GA-ANN model-based feature selection. Comput. Electron. Agric. 2020, 172,105352 [CrossRef]

40. Vishwakarma, D.K.; Pandey, K.; Kaur, A.; Kushwaha, N.L.; Kumar, R.; Ali, R.; Elbeltagi, A.; Kuriqi, A. Methods to estimate evapotranspiration in humid and subtropical climate conditions. Agric. Water Manag. 2022, 261, 107378. [CrossRef]

41. Singh, V.K.; Kumar, D.; Kashyap, P.S.; Singh, P.K.; Kumar, A.; Singh, S.K. Modelling of soil permeability using different data driven algorithms based on physical properties of soil. J. Hydrol. 2020, 580, 124223. [CrossRef]

42. Moriasi, D.N.; Gitau, M.W.; Pai, N.; Daggupati, P. Hydrologic and water quality models: Performance measures and evaluation criteria. Trans. ASABE 2015, 58, 1763-1785. [CrossRef]

43. Stamenković, L.J. Application of ANN and SVM for prediction nutrients in rivers. J. Environ. Sci. Health Part A 2021, 56, 867-873. [CrossRef]

44. Rahgoshay, M.; Feiznia, S.; Arian, M.; Hashemi, S.A.A. Modeling daily suspended sediment load using improved support vector machine model and genetic algorithm. Environ. Sci. Pollut. Res. 2018, 25, 35693-35706. [CrossRef]

45. Massah, J.; Vakilian, K.A.; Shabanian, M.; Shariatmadari, S.M. Design, development, and performance evaluation of a robot for yield estimation of kiwifruit. Comput. Electron. Agric. 2021, 185, 106132. [CrossRef] 